\title{
Making "Cuts" with a Holstein Cow in Early Childhood Education and Care: The Joys of Representation
}

\author{
Teresa K. Aslanian and Anna Rigmor Moxnes
}

Teresa K. Aslanian is an associate professor in the Department of Early Childhood Education, University of South-Eastern Norway. Her research is concerned with retheorizing early childhood education concepts and practices through critical and posthuman theories. Email: tea@usn.no

Anna Rigmor Moxnes is an associate professor in the Department of Early Childhood Education, University of South-Eastern Norway. Her research is concerned with early childhood education, kindergarten practices, and posthuman theories. Email: anna. moxnes@usn.no

This article explores children's play with representations of animals, specifically the Holstein cow, as noninnocent care practices in the context of early childhood education and care environments. We use Barad's relational ontology and Chaudhuri's concept of zooësis to activate a temporal diffractive analysis of memory stories about children's play with cows in ECEC read through facts from past, present, and future livestock-rearing practices. We connect the joy of playing with representations of nonhuman animals to the responsibility associated with multispecies lives, and to care as the production of flourishing.

Key words: care; representations; play; child-animal relations; temporal diffraction
Cow of mine, I thank you

Delicious milk you give to me

Every day, along with my bread

I drink your milk, so sweet

(Peter Andreas Jensen, "My

Cow, I Thank You")

Nonhuman animals and representations of such animals are ubiquitous in children's lives in early childhood education and care (ECEC) centres, as illustrated in the above meal song from 1873, still commonly sung by children and their educators at mealtimes. There is growing interest in the education sector for research on child-animal relations, with two recognizable branches of research. The first branch has been concerned with exploring nonhuman animals as a resource for learning about life cycles, birth, illness, death, taking responsibility, and care relationships,

with a particular interest in the care and empathy nonhuman animals seem to produce, teach about, and inspire (Meyers, 2007; Rud \& Beck, 2003).

A more recent branch of research problematizes the idealization of nonhuman animals as teachers and sources of care practices, focusing instead on the complexities of multispecies lives and care practices as noninnocent (Hohti \& Tammi, 2019; Taylor \& Pacini-Ketchabaw, 2015). Moving from a traditional understanding of care as connected to goodness, intention, and morality (Noddings, 2012), recent research is concerned with care as not necessarily only good or moral. Reminding readers that "nothing holds together without relations of care," Maria Puig de la Bellacasa (2017, p. 67) argues that care is more than (and not even necessarily) a moral activity. Living in a relational world requires care. Care relations therefore involve more than care as a human, moral, and pleasant activity. Care is ontological; care is being in a relational world. Care practices are entangled in nature/ culture and involve the complexities of relational worlds. To understand entanglements of care in animal-child relations requires both thinking with care (Puig de la Bellacasa, 2012, 2017) and an interest and a willingness to think with things. 
In this article, we explore children's play with representations of nonhuman animals, paying special attention to the Holstein cow, as noninnocent care practices in the context of ECEC environments. The term animal can imply a group inclusive of humans or exclusive of humans. For ease of reading, we will hereafter use the term animals or other animals to refer to nonhuman animals. To explore children's play with representations of animals, we have collected memory stories (Hohti, 2018; Moxnes, 2019; Moxnes \& Osgood, 2018) and facts from past, present, and future livestock-rearing practices which we carefully read with Karen Barad's (2017) relational ontology and the concept of zooësis (Chaudhuri, 2007) from the field of animal studies. Through our readings, we explore how relations between children and animals and representations of animals can involve care but not necessarily moral care. Rather, we argue that children and animals do care when playing with animal figurines, as they make agential cuts that contribute to the world's flourishing. Approaching children-animal relationships as temporal and material entanglements, this article contributes to knowledges about children-animal relationships as noninnocent practices of care and world making in ECEC. Thinking about the Holstein cow with care, for us, means approaching it with curiosity and being cognizant of its entanglements and our own entanglements with it as we follow memory stories along unexpected turns.

\section{Zooësis, play, and relational ontology}

The traditional meal song reproduced above (Jensen, 1873) tells the story of the cow as a giver of milk and child as appreciative receiver of its gift. Such social representations of animals in educational settings are problematized in critical animal studies for producing simplified stories about what animals are in relation to humans that render the complexities of animal-human care practices invisible (Linné \& Pedersen, 2013). Una Chaudhuri (2007) suggests the term zooësis to conceptualize the performative practices and discourses that permeate human-animal relations. The term denotes the state of being an animal, as defined by humans, through animal-human relations. We draw on the concept of zooësis to explore how the animals and humans in our collected memory stories perform in certain ways, according to certain roles, and how children may be socialized into these practices.

At the same time, we are fascinated by children's ability to also sidestep human-animal cultural roles, through play. Children's play is often described in early childhood literature either as a medium for language development, cognitive development, learning, and social skills (Änggård, 2016; Greenspan \& Lieberman, 1994; Steinsholt \& Øksnes, 2003,) or as children's particular mode of being (Greve et al., 2018). Play can also be understood as an active agent in itself (Steinsholt \& Øksnes, 2003). We understand play in light of Barad's relational ontology $(2007,2017)$ as coproduced intra-active processes. Play is something children do with otherthan-human materials, and representations of animals are often among these materials. As such, the intra-active play of children and representations of animals contributes to a "cultural animal unconscious" (Chaudhuri \& Enelow, 2006, p. 3), producing other discourses and cultural practices beyond animal as object of care, carer, or source of food, clothing, or protection.

Plastic animal figurines are to be found in most Norwegian ECEC centres and are among the props used along with storytelling as language materials that aid learning new words and terms in ECEC (Karsrud, 2014, p. 126). In such learning perspectives, representations of animals are often understood as static and objective descriptions of animals. As early as 1967, Donald Ball pointed to looking beyond the manifested features of toys and viewing them as agents rather than objects. We understand animals and animal toys in ECEC, not as a static source of learning about life cycles, mutual care, etc. (Cole \& Stewart, 2014), but as agents along with children enacting mutual world-making practices (Haraway, 2008, p. 287). 
Barad's $(2007,2017)$ relational ontology supports our view of toys as agents, drawing on quantum processes in which phenomena do not exist as independent entities but rather are always mutually producing each other through entanglements or intra-active processes of becoming. Thinking with relational ontology, we understand relations between the environment, children, and toys in ECEC, not as subject-object relations, but as mutually entangled phenomena that produce each other and affects within ECEC environments and beyond.

Any intra-action, according to Barad (2007), entails responsibility for what is enacted. Being responsible requires "taking account of the entangled phenomena that are intrinsic to the world's vitality and being responsive to the possibilities that might help it flourish" (Barad, 2007, p. 396). We read the responsivity to flourishing as a way to understand care as more than moral and more than human. We believe this orientation can provoke a release from habitual modes of perceiving care, children, and children's play (Hultman \& Lenz Taguchi, 2010) as independent phenomena. As intra-action, play can be described as children's potential involvements with the world's vitality and its flourishing.

An ethics of responsibility reminds us that space and time are not separate. Harm done in the world today shapes the world of the future. Drawing on descriptions of temporal diffraction in quantum physics, Barad (2017, p. 67) suggests that not only space but time involves entanglements. The idea of temporal diffraction challenges us to rethink time as distinct from place by exploring the ways in which time, space, and matter entangle and work through each other. The past is present in the future, entangled in places and things. Barad (2017, p. 69) explains temporality as "where the 'new' and 'old' might coexist" and "where each history coexists with the others" (p. 68). Diffraction patterns become, in Barad's words, "a manifestation of different times bleeding through one another" (p. 68).

Inspired by ideas of how stories inhabit each other, we sought out our own memory stories of the Holstein cow and the memories of our early childhood educator friends and colleagues. Our aim was to think with the Holstein cow and better understand the ways in which it was entangled with us in the time and space of our lives as early childhood educators. We spent ten days in the course of our daily lives talking among ourselves, friends we came across, and colleagues we met in the practice field and at universities about the Holstein cow. We were surprised to find that experiences with cows and representations of cows were commonplace and interwoven in ways not previously reflected upon. Using a plastic animal figurine of a Holstein cow as guide, in this article we weave collected memory stories of past entanglements with the Holstein cow in ECEC through reflections on livestock-rearing practices past, present, and future. Exploring what temporal diffractions make possible, we ask, how does the Holstein cow invite us to think differently about representation, play, and care?

\section{Thinking with a Holstein cow figurine}

The plastic figurine of a Holstein cow (Figure 1) stands out to us as perhaps the most common physical representation of animals in ECEC environments. Representation is problematized in postmodern literature as a subjugating force (Foucault, 1980; Kincheloe, 1997; MacLure, 2013). Representationalism asserts that representations reflect that which is represented. Foucault (1980) argued that representations do not merely reflect what already is but are part of what produce that which is by the discourses the representations produce. In other words, systems of power produce the subjects they subsequently come to represent. 


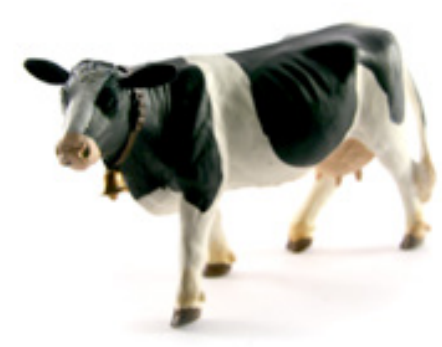

Figure 1. A plastic figurine of a Holstein cow.

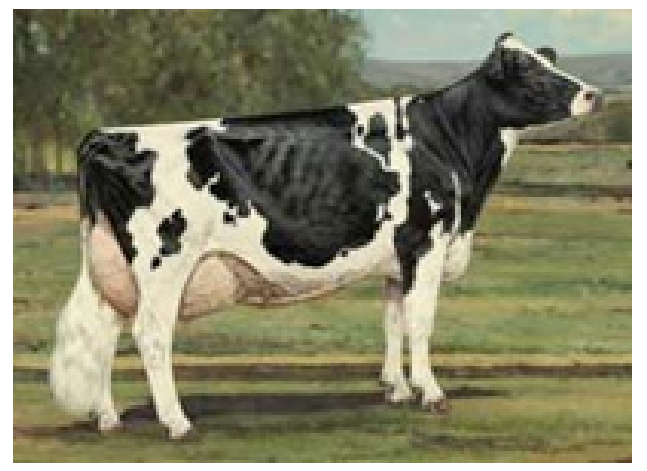

Figure 2. Painting of an ideal Holstein cow. Source: https://thewildanimalstore.com/product/holstein-cow-toy (used with permission).

An example of Foucault's thinking can be found in the miniature, plastic representation of a Holstein cow (Figure 1). Using this figurine as an example, children who do not live around cows but have access to the plastic figure that adults call "cow" will perhaps come to understand a cow as a somewhat emaciated creature, perhaps with a relatively large udder.

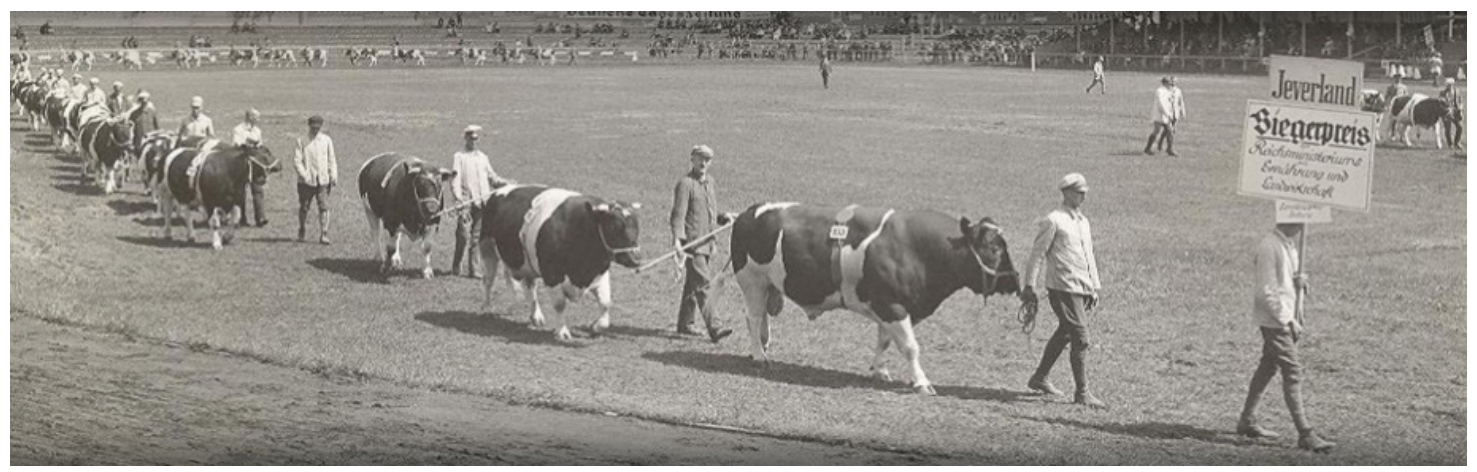

Figure 3. The Holstein cow before aggressive breeding.

The shape of the cow's body is the result of its relations with humans and 150 years of continuous breeding to produce high quantities of milk. The cow's bodily resources are sent to milk production rather than to producing 
muscle on the back and hips (Orland, 2003). The cow's friendly, hornless head is the result of systematic removal through breeding to avoid fighting in stalls (Bächi, 2016). The breed has been standardized for optimal milk production and the representation in the form of a plastic figurine normalizes the "standardized vision" (Grasseni, 2005, p. 48) of the Holstein cow (Figure 2). The Holstein cow is central to efforts at mapping genomes of animals to maximize economic gain. Prior to breeding for dairy production, the Holstein cow was visibly more muscular (Figure 3). The very genome of the Holstein cow in the United States has been changed as a result of breeding by the dairy industry through artificial selection for economically important traits, resulting in the economically desired increased milk production and a regrettable concomitant decrease in fertility and immunity (Ma et al., 2019). The cow transformed by humans through biopower into a milk producer is presented to children as simply a cow. Children learn to understand the Holstein cow as a willing producer of milk for the benefit of children and humankind (Cole \& Stewart, 2016). It would seem to a child that cows have large udders so that they can provide us with milk. The popular representation is tiny, meant to fit into the palm of a young child's hand and teach the child where the milk we drink comes from. The aggressive breeding of the Holstein cow illustrates a form of zooësis through a human-animal cultural and biological entanglement in which cows perpetually perform as producers of milk in response to human demand.

\section{Play, intra-action, and agential cuts}

Lina (3 years old) is smuggling out a black and white plastic cow figurine, hiding it in her pocket. When she comes outside, she hides behind the house, next to the cow fence. She makes a fence on the grass, using small sticks and stones, and places the plastic cow on her field. Then she lays down, watching the real cows on the other side of the fence, while slowly moving the smuggled cow figurine towards the crowd of cattle over the fence.

How does the Holstein cow become something different and more than an innocent farm animal or product of the dairy industry in the hands of children? Lina becomes another human producing and "playing" the Holstein cow as performer. Through play, she also becomes a world-maker with the cows, whose aliveness complicates representations with unpredictable elements. Lina's engagements with the plastic cow and the real cows are materialized cultural practices, but in the ongoing materialization, there is also imagination and intra-action. Lina's meeting with cows' situation in the world and her imagination produces new representations: a fence, like the one that restrains the real cows, is made from the sticks and stones of the forest ground. The sticks become something else in Lina's hands. Worlds being created trouble the binaries between micro and macro, nature and culture, nonhuman and human, real and imaginary (Barad, 2017, p. 56). The real is involved with the pretend, and the child's play produces new borders of real and unreal, inside and outside.

Challenging the tradition of representation, Barad (2007, p. 137) argues that it relies on an underlying idea of the preexistence of entities. From an agential-realist perspective, a Holstein cow does not actually exist, because phenomena are constantly becoming through intra-active relations. The representation of a Holstein cow therefore describes a nonexistent subject as if it were stable, as if it were something. Representations are actually more like manifestations, images of an idea that is always in the past, a trace of myriad intra-actions.

To understand representations as intra-actions (Leahu, 2012; Timeto, 2011), we can consider Barad's concept of the agential cut. Agential cuts are temporary enactments of apparent separation of agential phenomena produced within an apparatus (Barad, 2007). In quantum physics, particles can occupy superpositions, which means they can, in a way, be anywhere until they are measured. Upon measurement, entangled particles "take their places," positioning themselves differently according to how they are measured, so that, until measured, the particles exist both "here" and "there." Things, though indeterminate and being produced through intraaction, are perceived as distinct and become distinctive when viewed through a particular apparatus. 
An agentic cut can be likened to a measurement - that act of breaking in and observing or disturbing the superposition, the neither here nor there-ness. A "cut" defines what is made to be present and what is made to be absent. Engaging with various apparatuses enacts change and produces desired and sometimes undesired agential cuts (i.e., changes in the world, world making). When we view Lina's play with the cow figurine as a practice of making agential cuts, the figurine is not a reflection or static image, but an actor that is shaped by and shapes the world through intra-active engagements.

\section{Cuts make things present, but where does the absence go?}

Agential cuts are described as violent (Barad, 2014) and enacting change upon the world. Children's play enacts cuts, change, and transformation in a peculiar way. Children's play involves representations that do not have a stable representational content and are not generalizable (Luntley, 2018). Play is a thinking/doing/being in which that which is thought, done, and becomes is nongeneralizable but makes sense only in its particular becoming as an entanglement. We want to connect children's play with representations of animals with the concept of the void (Barad, 2017). Drawing on both Derrida's concept of the void as something that is both present and absent and the concept of the void in quantum field theory, Barad (2017) describes the void as an aspect of the ephemeral nature of the world. The world, which is a becoming, requires a void which is nothingthe absence of beingness, and therefore the cauldron of possibility, of becoming. All that becomes springs out from the void and continues to be entangled in the void. Absence, at a quantum level, is entangled in presence. Barad (2017) connects the void to imagining and we connect it to children's excess imagination relative to adults. We suggest that the presence of absence - the void - allows children and adults alike to understand a plastic figurine as a cow and for children to understand it in another moment as something else entirely. We relate children's play with the void to MacLure's (2013) description of the practice of nonrepresentational research, which includes being "caught up in the momentum of becoming" (p. 662, italics in original) and the act of "surfing' the intensity of the event that has caught us up, in order to arrive somewhere else" (p. 662). In the following memory story, we follow two young boys playing enthusiastically with plastic animal figurines, seemingly without considering what the figurines are meant to represent, but rather surfing the intensity, and becoming with.

In the corner is a shelf, and on that shelf a red box full of plastic farm animals, including the Holstein cow. Each morning the box is emptied into a doll-carriage. Two boys, 2-and-a-half years old, speed-drive the doll carriage full of plastic animals to the opposite corner of the room. Here they dump the contents of the carriage, spin around the room for a few minutes, and then return to the animals and shovel them back into the carriage. A new corner is found and the animals dumped. They are lying on the floor ready to be shovelled back into the carriage when it, sooner or later, returns from its spinning voyage around the room.

A staff member enters the room. She watches the scene for a few seconds before picking up the red box and starting to put the animals back into it. She explains to the boys that they have to take care of the animals. They are meant to be played with as animals on a farm. She illustrates it by holding up each species one by one, stroking them with her hand, and pronouncing their names loudly and clearly-c-o-w-and the sound it makes-m-o-o. The boys are standing still, watching her. The next morning, the scenario with the animals and doll carriage is repeated-no stroking the animals, only dumping them. Later, through conversation, the boys share with their teacher that they were dumping building materials.

When the boys played with their toys, the figurines' representational content was not determined by the visible signs and manifestations of representation, but by the logic of the world the boys and toys were making. Matter was not assigned a stable meaning, but together they were performing ongoing new meanings, in a joyful process 
of world making. Any apparatus has a particular shape that is "the properties of the 'components' of phenomena" that "become determinate and ... meaningful" (Barad, 2003, p. 815). For the children in this story, their ECEC centre was an apparatus, and the animal figurines had a certain role in that apparatus-a learning about life and death role, a learning about caretaking role, and a learning about where food comes from role. Through play, the children navigated the apparatus with unexpected moves, reconfiguring the cultural meaning of and performance of animal-human relations in unique and fluid ways. Pretend play has been described as relating "in its own special ways to other activities" (Binkley, 1974, p. 568).

In some ways, toys as representations of other things can also be understood as intra-actions. For example, when playing with young children, we have observed that educators often refer to toys as the creatures or objects they represent. Educators and children alike play this game, even before any pretend or play has begun. When we are calling a plastic figurine of a cow "a cow," we are making it a cow, and it is becoming cow. While these may be the ways educators understand the figurines and intend them to be used, children may and often do understand objects differently (Aslanian, 2018) and use them in a variety of ways - not necessarily as animals at all. A plastic figurine of a cow can be building materials-or anything imagined in the intra-action. When children act with plastic animal figurines in unintended ways, they are engaging in productive, intra-active, relational processes.

The difference between the way the children used the figurines and the way the educator used the figurines reminds us of Bohr's story, retold by Barad (2007) to describe agential cuts, of a blind person with a stick:

When the stick is held loosely, it appears to the sense of touch to be an object. When, however, it is held firmly, we lose the sensation that it is a foreign body, and the impression of touch becomes immediately localized at the point where the stick is touching the body under investigation. (Bohr, 1963, p. 99, as cited in Barad, 2007, p. 154)

Barad goes on to explain how the stick can or cannot be used to feel one's way around a darkened room.

The stick cannot usefully serve as an instrument of observation if one is intent on observing it. The line between subject and object is not fixed, but once a cut is made (i.e., a particular practice is being enacted), the identification is not arbitrary but in fact materially specified and determined. (pp. 154155)

When the stick is held firmly, it becomes an instrument with the body and can be used to feel about a darkened room. The adults observed the plastic figurines and identified them according to their intended representations, metaphorically holding the figurines loosely, as objects, as static representations, while the children used the figurines and the doll carriage as subjects, extensions of themselves and instruments in the world. The same figurine acts in different ways according to what practice is being enacted.

The above narrative begins with excited play and ends with excited play, but in the middle, a staff member tries to change the play into something more recognizable, seeing the figurines as static and in terms of the apparatus she was a part of and being produced by. The plastic animals were being dumped here and there, rather than being treated the way children in the centre were expected to treat them, as objects representing animals that teach about care. We suggest that the children were rather thinking with the animal figurines and together with them, in this sense, doing care through engaging with figurines as instruments for the production of shared vitality.

\section{The complex joys of representation}

For very young children without an abundance of representational capacity and experience, toys seem to 
function as "open" representations and potentialities (Luntley, 2018). The representations themselves are toys to play with. For children, representations of animals are not necessarily reductions, but doors into the void (Barad, 2017) where new possibilities can come to life. The development of representational capacity allows children to relate to the outside world and understand themselves as separate from it (Greenspan \& Lieberman, 1994). The ability and desire to represent is thus a part of mental functioning necessary to interact in a complex world.

Returning to Lina, the readily available sticks and stones become a fence with Lina's hands engaging in representation as play. The wooden fence Lina observes keeps the living cows away from her, while the fence she builds brings the cows closer to her, through play, creation, and imagination. Rather than understanding representations as reductions of phenomena, we suggest that representations are also open ended and continually in flux. This aspect of representation is embraced when children play with representations, or toys. Children's play with representations of animals sidesteps static understandings and instead engages in ongoing and iterative materializations of the world, entangling agricultural practices with education and the joy of play. We read the concept joy as nuanced and something other than happiness and find support in differing between happiness and joy when reading Donna Haraway (2008). She points to joy as deeper: as something that shines from inside out, something caused all around (Haraway, 2008, p. 241). For Rosi Braidotti (2017), joy is about an ethical ideal, or aspiring "to the joyful affirmation of virtual possibilities, of what 'we' are capable of becoming" (p. 24). Joy in this sense is intimately connected to the void, as a place of becoming.

By paying attention to children's play with representations of animals as intra-actions, we flip the picture, from a human-centered view of objects being the result of humans doing and producing, to a posthuman view of what nonhumans and humans produce together. In so doing, we open opportunities to discuss representations as contributions and generative forces for change. We propose that, rather than the animal figurines inspiring learning about care as the educator expected, the children, along with the animals, did care, insofar as they together produced new possibilities, new ways to be, and thus participated in the production of flourishing and the "vitality of the world" (Barad, 2007, p. 396). The stories told through children's play with toys and stories told through the educators' understandings of how toys should be used coexist side by side. They diffract when they are read together and create new and other stories. In our reading, children-animal relations involve both more than moral care taken and, at the same time, not "necessarily moral" caretaking. Relationships involve noninnocent care, as an amoral world-making activity and ontological force (Puig de la Bellacasa, 2017). Through play, children and animal figurines produce new relationships, joy, flourishing, and vitality without the aim of being good or doing right. Similarly, children's play with representations of animals is also unintentionally taking part in troubling human-nonhuman animal practices.

\section{Entanglements with living Holstein cows}

Cow figurines are often marketed as seemingly caring families (bull, cow, and calf; Figure 4). The farm is often portrayed as a place where animals and humans live together in peace (Linné \& Pedersen, 2017). One of our favourite songs to sing in early childhood settings, "My Cow, I Thank You" (Jensen, 1837), reproduced at the beginning of this article, tells this story. As early childhood educators, singing this song before a meal with the children brought us feelings of gratitude and proximity to nature. The sentimental emotions we felt when singing "My Cow, I Thank You" cast a peculiar light, however, when thinking with the rearing practices in the worldwide dairy industry. The idealized happy cow family is not materialized through dairy farm practices. For farmers to run a dairy farm, they must ensure that their cows produce a high quantity of milk. To meet the economic demands of the dairy farming industry, cows must produce milk constantly. To achieve constant lactation, the cow is inseminated once a year to birth a calf. Calves are taken away from their mothers, either directly 
after birth or after a couple of days. These calves are either slaughtered after about eighteen months for meat production or selected as future dairy cows (Linné \& Pedersen, 2017, p. 114). The milk we have been thanking cows for is not being offered to their own offspring but being taken for ours. The song tells the story of cows giving delicious milk, as a gift. A cow is imagined as having both agency and benevolence toward humans. Some accounts of human-animal relations emphasize the agency and emotional labour of cows who produce milk for humans (Linné \& Pedersen, 2017), suggesting cows are cooperating with farmers to produce milk.

I remember walking through a friend's barn listening to her talking about how she cares for her cows. She explained how her stock was brought up from the stock of her parents, grandparents, great-grandparents, and so on. The farmer and her cows were deeply rooted on the farm.

Though the industrialized farm and this small family farm tell different stories of colonization and biopower, the past shapes the present. The 150 years of breeding of the Holstein cow is visibly present in real cows and in the toy figurines (Figure 4) being sold as a happy family belonging to a cozy farm.

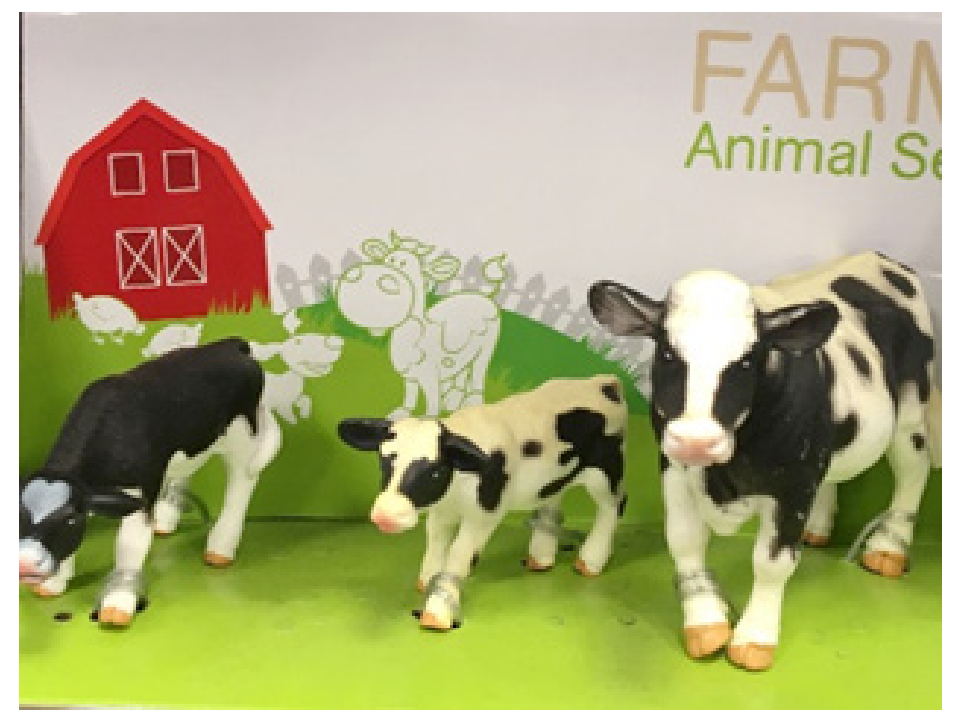

Figure 4. Farm animal set found for sale at a gas station in Norway. Photo credit: Teresa Aslanian.

The taste and nutritious quality of cows' milk depends on what the cows eat. The second and third verse of the traditional song "My Cow I Thank You" are less well known and not usually included in the meal song, but they describe what makes the milk so delicious. The full song was included in Norway's first textbook for schools in 1873.

Don't take the withered straw

Eat instead the juicy grass!

Grass makes your milk so sweet

Here is the field, so wet and fresh

Here, the beautiful flowers grow

Here, the little creek flows

Here, you find food in scrubs and paths

Eat well, my dear cow.

Jensen, 1873 
Most cattle in Norway spend most of their days in a small compartment without much freedom of movement. Concern for animal well-being and a growing awareness of repercussions for animal health-and thus productivity-is generating increasing pressure on farmers to shift to free stalls in which cows can move about freely through the day. The Norwegian parliament has decided that all cows will be kept in free stalls by the year 2034 (Lovdata, 2019). The law guarantees cows that live in free stalls outdoor freedom of movement for at least eight weeks during the summer. For cattle who live in small compartments without freedom of movement inside the stall, a full 16 weeks of outside freedom of movement are required. These measures are the result of concern for animal welfare, but the concern is positioned in an economic framework in which the happiness of cows is always measured against the potential for economic gain or loss (Asdal \& Druglitrø, 2017, p. 68; Bächi, 2016).

Earlier we argued that representations are like traces of myriad intra-actions and that agential cuts are temporary enactments. We see the representation of the Holstein cow as enactments of cattle living 36 weeks a year in a stall, as a small plastic cow figurine in Lina's hand, the husky body of the Holstein cow before aggressive breeding (Figure 1), the large udder on the modern ideal cow (Figure 2), the happy cow family, and the farmer talking about her care and devotion to her cows, deep caring roots, and milking-machines.

Splash! A cow let go of a cow patty just next to me. I jump, but too late-grey/brownish, stinking cow manure up my legs and on my new yellow shoes...

\section{Letting the cows out}

Fields surround the early childhood education centre. Each spring the farmer lets the cows out, and on that day, watching the cows coming out is the big happening for all the children and adults in the centre.

Turning back to the joy of making cuts, we invite you to watch the following video: https://www.youtube.com/ watch? $=$ LVWQzYi0URc

The responsible practice of assuring cows' freedom of movement outdoors during summer months has produced a ritual that occurs every spring when the cows are let out. The event is a pasture release that locals often gather to watch. Visitors come to see the cows set free into green pastures as they hop and run like dogs or sheep, playing with each other, eating the fresh grass and trotting around. The cows are clearly overwhelmed with joy as they are set free into green pastures and the people who come to watch are visibly moved by the cows' expressions of joy. At the same time, their heavy, milk-filled udders restrict their movement and tell another story. Materialized in the letting out of the cows, we find the entanglement of human-cow relationships is awakened as the cows are released from a winter of closed quarters and, from the perspective of critical animal studies, their ongoing emotional labour (Linné \& Pedersen, 2017, pp. 118-119).

The cow, including the plastic representation, facts from livestock rearing, and the memory stories, has, together with Barad's $(2007,2017)$ thinking, helped us to shift our perspective from representation as static and objective reduction to representation as intra-active, potentially generative, and part of the more-than-human world. Thinking with the Holstein cow through temporal diffractive readings of memories and artefacts, along with the concept of zooësis, has sparked complexities of care and comfort, utility, tradition, and ethically complicated (joy) practices. Through the various cuts, we have struggled to become with the Holstein cow in childhood settings, with past and present practices in cattle industries materialized in social representations of animals in the hands and lives of children. We have argued that understanding children's play with representations of animals as making cuts sheds light on representations as intra-actions and play with animals as a form of care in ECEC environments and, in a broader sense, children's participation in world making. Children's relationships 
to plastic figurines of animals involved reconfiguring cultural practices, ideas, and performances of humananimal through making agential cuts, sidestepping the limitations of the apparatus of ECEC and taking part in the "world's vitality" (Barad, 2007, p. 396). We have explored child-animal relations that involve care, but not innocent care. Rather, care as practiced through the flourishing that children and animals produce together through imaginative intra-active play. Employing temporal diffraction with zooësis produced the possibility to view the mingling of human-animal social practices and the joys of representations available in children's play that offer opportunities for other-than-human animals and human animals to become otherwise.

In the autumn, when the cows are back in their stall, the children take over the field. Skipping around, they run like mad, jumping over old, dry cow patties in seeming joy.

\section{Acknowledgements}

We would like to thank the kindergarten staff members and colleagues who generously shared their memory stories with us. We also want to thank our reviewers for thoughtful comments and suggestions that pushed our thinking further along. Thanks also to University of South-Eastern Norway for the research grant that allowed us to delve into child-animal relations in ECEC. 


\section{References}

Änggård, E. (2016). How matter comes to matter in children's nature play: Posthumanist approaches and children's geographies. Children's Geographies, 14(1), 70-99. https://doi.org/10.1080/14733285.2015.1004523

Asdal, K., \& Druglitrø, T. (2017). Modifying the bio-political collective. In K. Asdal, T. Druglitrø, \& S. Hinchliffe (Eds.), Humans, animals and biopolitics: The more-than-human condition (pp. 66-84). Routledge.

Aslanian, T. K. (2018). Recycling Piaget: Posthumanism and making children's knowledge matter. Educational Philosophy and Theory, 50(4), 417-427. https://doi.org/10.1080/00131857.2017.1377068

Bächi, B. (2016). What is a cow? The invention of the freestall and how cows lost their horns. In K. Bjørkdahl \& T. Druglitrø (Eds.), Animal housing and human-animal relations: Politics, practices, and infrastructures (pp. 29-42). Routledge.

Ball, D., W. (1967). Toward a sociology of toys: Inanimate objects, socialization, and the demography of the doll world. The Sociological Quarterly, 8(4), 447-458. https://doi.org/10.1111/j.1533-8525.1967.tb01081.x

Barad, K. (2003). Posthumanist performativity: Toward an understanding of how matter comes to matter. Signs: Journal of Women in Culture and Society, 28(3). https://www.uio.no/studier/emner/sv/sai/SOSANT4400/v14/pensumliste/barad posthumanistperformativity.pdf

Barad, K. (2007). Meeting the universe halfway: Quantum physics and the entanglement of matter and meaning. Duke University Press.

Barad, K. (2014). Diffracting diffraction: Cutting together-apart. Parallax, 20(3), 168-187. https://doi.org/10.1080/13534645.2014.9276 $\underline{23}$

Barad, K. (2017). Troubling time/s and ecologies of nothingness: Re-turning, re-membering, and facing the incalculable. New Formations, 92, 56-86. https://doi.org/10.3898/NEWF:92.05.2017

Binkley, T. (1974). Real and pretend. Philosophy and Phenomenological Research, 34(4), 560-568.

Braidotti, R. (2017). Posthuman, all too human: The memoirs and aspirations of a posthumanist. Tanner Lectures, Yale University.

Chaudhuri, U. (2007). (De)facing the animals: Zooësis and performance. TDR—The Drama Review, A Journal of Performance Studies, 51(1), 8-20. https://doi.org/10.1162/dram.2007.51.1.8

Chaudhuri, U., \& Enelow, S. (2006). Animalizing performance, becoming-theatre: Inside zooësis with The Animal Project at NYU. Theatre Topics, 16(1), 1-17. https://doi.org/10.1353/tt.2006.0004

Cole, M., \& Stewart, K. (2016). Our children and other animals: The cultural construction of human-animal relations in childhood ( $2^{\text {nd }}$ ed.). Routledge.

Foucault, M. (1980). Power/knowledge. Pantheon.

Grasseni, C. (2005). Designer cows: The practice of cattle breeding between skill and standardization. Society \& Animals, 13(1), 33-49. https://doi.org/10.1163/1568530053966652

Greenspan, S. I., \& Lieberman, A. F. (Eds.). (1994). Representational elaboration and differentiation: A clinical-quantitative approach to the clinical assessment of 2- to 4-year-olds. Oxford University Press.

Greve, A., Kristensen, K. O., \& Wolf, K. D. (2018). Lekens status og vilkår i barnehagen. In S. Østrem (Ed.), Barnehagen som samfunnsinstitusjon (pp. 86-105). Cappelen Damm.

Haraway, D. J. (2008). When species meet. University of Minnesota Press.

Hohti, R. (2018). Siiri and the "Bag Lady." Reconceptualizing Educational Research Methodology, 9(1), 6-16. https://doi.org/10.7577/ $\underline{\text { rerm. } 2698}$

Hohti, R., \& Tammi, T. (2019). The greenhouse effect: Multispecies childhood and non-innocent relations of care. Childhood. https://doi. 
org/10.11770907568219826263

Hultman, K., \& Lenz Taguchi, H. (2010). Challenging anthropocentric analysis of visual data: A relational materialist methodological approach to educational research. International Journal of Qualitative Studies in Education, 23(5), 525-542. https://doi.org/10.1 $\underline{080 / 09518398.2010 .500628}$

Jensen, P. A. (1873). Loesebog for folkeskolen og folkehjemmet. Cappelen. https://urn.nb.no/URN:NBN:no-nb digibok 2009020600097

Karsrud, F. T. (2014). Muntlig fortelling i barnehagen. Cappelen Damm Akademisk.

Kincheloe, J. (1997). Fiction formulas: Critical constructivism and the representation of reality. In W. G. Tierney \& Y. S. Lincoln (Eds.), Representation and the text: Reframing narrative voice (pp. 57-88). SUNY Press.

Leahu, L. (2012). Representation without representationalism (Doctoral dissertation). Cornell University, Ithaca, New York.

Linné, T., \& Pedersen, H. (2013). With care for cows and a love for milk: Affect and performance in Swedish dairy industry marketing strategies. In A. Potts (Ed.), Meat culture (pp. 109-128). Brill.

Lovdata.(2019).Forskriftom holdavstorfe [Regulations on thekeeping of cattle].https://lovdata.no/dokument/SF/forskrift/2004-04-22-665

Luntley, M. (2018). Play's the thing: Wherein we find how learning can begin. Journal of Philosophy of Education, 52(1), 36-53. https:// doi.org/10.1111/1467-9752.12279

Ma, L., Sonstegard, T. S., Cole, J. B., VanTassell, C. P., Wiggans, G. R., Crooker, B.A., Tan, C., Prakapenka, D., Liu, G. E. \& Da, Y. (2019). Genome changes due to artificial selection in U.S. Holstein cattle. BMC Genomics, 20(1), 1-14. https://bmcgenomics. biomedcentral.com/articles/10.1186/s12864-019-5459-x

MacLure, M. (2013). Researching without representation? Language and materiality in post-qualitative methodology. International Journal of Qualitative Studies in Education, 26(6), 658-667. https://doi.org/10.1080/09518398.2013.788755

Meyers, G. (2007). Social development and our connections to other species. Purdue University Press.

Moxnes, A. R. (2019). working across/within/through academic conventions of writing a PhD: Stories about writing a feminist thesis. In G. Crimmins (Ed.), Strategies for resisting sexism in the academy (pp. 247-265). Springer.

Moxnes, A. R., \& Osgood, J. (2018). Sticky stories from the classroom: From reflection to diffraction in early childhood teacher education. Contemporary Issues in Early Childhood, 19(3), 297-309. https://doi.org/10.1177/1463949118766662

Noddings, N. (2012). The caring relation in teaching. Oxford Review of Education, 38(6), 771-781. https://doi.org/10.1080/03054985.20 $\underline{12.745047}$

Orland, B. (Ed.) (2003). Turbo-cows. About the production of a competitive animal in the 19th and early 20th century. Rutgers University Press.

Puig de la Bellacasa, M. (2012). "Nothing comes without its world": Thinking with care. Sociological Review, 60(2), 197-216. https://doi. org/10.1111j.1467-954X.2012.02070.X

Puig de la Bellacasa, M. (2017). Matters of care: Speculative ethics in more than human worlds. University of Minnesota Press.

Rud, A. G., \& Beck, A. M. (2003). Companion animals in Indiana elementary schools. Anthrozoös, 16(3), 241-251. https://doi.org/10.2752/089279303786992134

Steinsholt, K., \& Øksnes, M. (2003). Kunsten å fange øyeblikket- et essay om lek som improvisasjon. Norsk Pedagogisk Tidsskrift, 1-2, $55-68$.

Taylor, A., \& Pacini-Ketchabaw, V. (2015). Learning with children, ants, and worms in the Anthropocene: Towards a common world pedagogy of multispecies vulnerability. Pedagogy, Culture, \& Society, 23(4), 507-529. https://doi.org/10.1080/14681366.2015.1 039050 
Timeto, F. (2011). Diffracting the rays of technoscience: A situated critique of representation. Poiesis \& Praxis: International Journal of Ethics of Science and Technology Assessment, 8(2-3), 151-167. http://doi.org/10.1007/s10202-011-0099-5 